\title{
Análisis de las imágenes del cuerpo humano en libros de texto españoles de primaria ${ }^{1}$
}

\section{Analysis of human body images in Spanish primary school textbooks}

\author{
Asunción López-Manjón, Yolanda Postigo \\ Universidad Autónoma de Madrid \\ asuncion.lopez.manjon@uam.es, yolanda.postigo@uam.es
}

RESUMEN: Las imágenes utilizadas en la enseñanza, consideradas como sistemas externos de representación, suponen un desafío educativo debido a las numerosas dificultades que tienen los estudiantes con este tipo de material. El objetivo del trabajo es determinar si el tratamiento de las imágenes en los libros de texto seleccionados facilita su aprendizaje. Analizamos las imágenes sobre el cuerpo humano de libros de $3 .^{\circ}, 4 .^{\circ}$ y $6 .^{\circ}$ cursos de educación primaria de tres editoriales españolas. Examinaremos si hay diferencias entre editoriales y si existe algún tipo de secuenciación del uso de las imágenes a través de los cursos. Analizaremos el número, tamańo, tipo de imagen, presencia o ausencia de componentes visuales y verbales de la imagen, y si existe referencia a la imagen en el texto. Los resultados muestran que el tratamiento dado a las imágenes no ayuda a superar las dificultades con las que se enfrentan los estudiantes, al no incluir recursos específicos que podrían guiar su interpretación. La comparación entre las editoriales indica que una de ellas proporciona significativamente más recursos que las otras para el aprendizaje a partir de las imágenes. Aunque escasos, existen algunos criterios de secuenciación de las imágenes a lo largo de los cursos.

PALABRAS CLAVE: imágenes; libros de texto; biología; educación primaria; dificultades de aprendizaje.

ABSTRACT: The images used in teaching, considered as external systems of representation, suppose an educational challenging because of the many difficulties students have when they faced with this type of learning material. The aim of this work is to determine to what extent the treatment that is made from the images in the selected textbooks facilitates student learning. We analyzed the images on the human body that appear in textbooks $3^{\text {rd }}, 4^{\text {th }}$ and $6^{\text {th }}$ year of primary school in three Spanish publishers. We examined whether there are differences between publishers and if there is any sequencing approach using images through the school years. We analyzed number, size, and type of image, presence or absence of visual and verbal components and if there are references of the text to the image. Results show that the treatment given to the images does not help especially to overcome the usual difficulties faced by students as they do not include specific resources that could guide their interpretation. The comparison among publishers indicates that one of them provides significantly more resources for learning from images. Although rare, there are some sequencing criteria of images along the courses.

KEYWORDS: images; textbooks; biology; primary education; learning difficulties.

Fecha de recepción: octubre 2013 • Aceptado: mayo 2014

1. Este trabajo forma parte del proyecto de investigación EDU2010-21995-C02-01. Financiado por el antiguo Ministerio de Ciencia e Innovación del Gobierno español.

López-Manjón, A., Postigo, Y. (2014) Análisis de las imágenes del cuerpo humano en

libros de texto españoles de primaria. Enseñanza de las Ciencias, 32.3, pp. 551-570 


\section{INTRODUCCIÓN}

El libro de texto es el material educativo al que más investigaciones se le han dedicado debido a su importante papel en los procesos de enseñanza-aprendizaje, principalmente en la educación primaria y secundaria (del Carmen y Jimenez-Aleixandre, 1997; Perales, 2006; Perales y Vilchez-Gónzalez, 2012). En los últimos años, según Lee (2010), ha habido un incremento del número de imágenes por página en los libros de texto, el doble que hace cincuenta años. Este incremento no se ha hecho a expensas del texto ya que este se mantiene. Sin embargo, son muy escasas las investigaciones sobre el papel y el uso de las imágenes de los libros de texto (Carvalho, Tracana, Skujiene y Turcinaviciene, 2011; Jiménez, Hoces y Perales, 1997; Jiménez y Perales, 2002; Maldonado, González y Jiménez, 2007; Matus, Benarroch y Perales, 2008; Otero, Moreira y Greca, 2002; Perales y Jiménez, 2002; Pozzer y Roth, 2003; Silva y Compiani, 2006; Soyibo, 1994; Stylianidou y Ogborn, 2002).

\section{Características de las imágenes}

Las imágenes, como un sistema externo de representación (Andersen, Scheuer, Pérez-Echeverría y Teubal, 2009; Martí y Pozo, 2000; Pérez-Echeverría, Martí y Pozo, 2010), son sistemas culturales de símbolos y signos generados por la comunidad científica (por ejemplo, la notación matemática, la geometría, formulación química, etc.) para representar su objeto de estudio. En este sentido, las imágenes, en tanto que representaciones visuales, tienen como rasgo característico que pueden representar de forma integrada grandes cantidades de información y conocimiento relacionados entre sí de forma compleja (Barquero, Schnotz y Reuter, 2000), o información que es difícil describir mediante palabras (Roth, Pozzer y Han, 2005). También las imágenes se caracterizan por poseer una naturaleza espacial, ya que son marcas realizadas en el espacio (Martí, 2003), de ahí que también se las denomine representaciones visuespaciales. Aunque tanto la naturaleza visual como espacial son comunes a todas las representaciones visuales, existe una gran heterogeneidad de representaciones visuales dependiendo del tipo de relaciones que expresan (conceptual, numérica, espacial, denotativa, etc.) (Pérez-Echeverría, Postigo, López-Manjón y Marín, 2009), así como del tipo de contenido que representan, por ejemplo, los mapas meteorológicos o el cuerpo humano. Serían representaciones visuales las fotografías, las microfotografías, los planos, los mapas conceptuales y geográficos, los diagramas visuales y de flujo, las gráficas cartesianas, los dibujos, las tablas, los esquemas, etc. El aprendizaje de estos sistemas es muy costoso, pues supone convertirlos en representaciones internas mediante un proceso de re-construcción y no en una simple apropiación mediante procesos asociativos o de copia. Para ello, los estudiantes necesitan activar procesos de aprendizaje muy complejos, lo que supone generalmente muchas dificultades, por ejemplo en biología (López-Manjón y Postigo, 2009), física (Colin, Chauvet, y Viennot, 2002), gráficas numéricas (Postigo, Pérez-Echeverría y Marín, 2010; García y Perales, 2007), mapas (Lowe, 1993; Postigo y Pozo, 2004), tablas (Martí, García-Mila, Gabuccio y Konstantinidou, 2011) e incluso en estudiantes universitarios (Bowen y Roth, 2002; Pérez-Echeverría, Postigo y Marín, 2010), y cuya superación requiere una enseñanza explícita.

\section{Dificultades de los estudiantes con las imágenes}

Una de las principales dificultades que encuentran los estudiantes ante una imagen es que su interpretación tiende a estar limitada a las características superficiales de esta, es decir, a sus aspectos perceptivos, y no guiada por los conceptos que pretenden representar (Bowen y Roth, 2002; Lowe, 1993; Patrick, Carter y Wiebe, 2005). Otra dificultad es que la interpretación de las imágenes no es unívoca ya que depende de varios factores, como por ejemplo la intención del autor, el conocimiento previo 
del lector, el tipo de imagen, la tarea demandada, el contexto y su contenido. Ante esta polisemia característica de las imágenes, incluso en el caso de las fotografías (Pozzer y Roth, 2003), el estudiante tiene dificultades para decidir qué significado debe atribuir a la imagen si no dispone de una ayuda específica que le ayude a restringir y elegir la interpretación adecuada (Lowe, 1993 y 2007). Por otra parte, para la apropiada interpretación de las imágenes se requiere conocer los códigos, las reglas o la sintaxis que subyacen a una imagen. Así, Constable, Campbell y Brown (1988), en un estudio sobre la comprensión de imágenes con cortes de estructuras anatómicas, encontraron que los estudiantes tenían problemas para interpretarlas porque desconocían las convenciones empleadas. Pero las dificultades no solo residen en la interpretación de la imagen sino también en su producción, sirviendo como herramientas para pensar o solucionar problemas (Kindfield, 1993/1994) o para simplemente comunicar información (Barquero, Schnotz y Reuter, 2000). Producir una imagen es un proceso muy complejo que implica tener en cuenta varios factores, como decidir qué representar, planificar cómo se va a representar de acuerdo con las intenciones comunicativas, saber a quién va dirigida, elegir el código representacional que se va a utilizar, etc. Por último, otra de las dificultades más importantes que tienen los estudiantes es comprender que las imágenes son representaciones de fenómenos y no los fenómenos en sí. Pero ello supone pasar de una concepción epistemológica realista a una concepción constructivista sobre las imágenes como sistema externo de representación, lo cual implica procesos de enseñanza-aprendizaje muy complejos (Postigo y López-Manjón, 2012a).

Teniendo en cuenta estas dificultades, nos interesa conocer hasta qué punto los autores de los libros de texto son conscientes del desafío educativo que suponen las imágenes como material de aprendizaje. El análisis de las imágenes de libros de texto de primaria sobre el sistema digestivo llevados a cabo en España (Pérez de Eulate, Llorente y Andrieu, 1999) y Portugal (Carvalho, Silva y Clément, 2007) concluye que el diseño de las imágenes puede reforzar los errores y las ideas alternativas que tienen los estudiantes debido a la superposición de formas y uso de colores poco contrastados que no permite discriminar unos órganos de otros. Soyibo (1994) también encontró algunos problemas en libros de texto de biología, por ejemplo diagramas en los que algunas estructuras no tenían etiquetas o estaban etiquetadas en plural o eran incorrectas, junto a flechas que señalaban espacios vacíos. Otros estudios con libros de texto de primaria sobre el cuerpo humano (López-Manjón y Postigo, 2008; Postigo y López-Manjón, 2012b) mostraron ausencia de rótulos y títulos y escasa referencia explícita a las imágenes en el texto principal (Perales y Jiménez, 2002). Las actividades con imágenes que se proponen en los libros de texto son de tipo reproductivo, limitándose a copiar, y rara vez incluyen actividades de producción (Soyibo, 1994). En resumen, las investigaciones parecen indicar que el diseño de las imágenes en los libros de texto no tiene en cuenta las dificultades que supone el aprendizaje de este material. Por tanto, podríamos concluir que los libros de texto asumen una concepción sobre la enseñanza y aprendizaje según la cual las imágenes se procesan de manera automática, son autoevidentes y transparentes (Lowe, 1993), son fáciles de aprender y su enseñanza se limita a presentar la imagen correctamente para que se pueda copiar (Fanaro, Otero y Greca, 2005). De hecho, esta concepción es la que pudiera explicar la escasa relación entre los procesos editoriales responsables de la elaboración del texto principal y la elaboración de las imágenes que acompañan al texto.

El objetivo de este trabajo es analizar el tratamiento de las imágenes sobre el cuerpo humano incluidas en libros de texto de educación primaria de diferentes editoriales y cursos. Específicamente, las preguntas que queremos responder en este estudio son las cuatro siguientes:

- ¿Qué importancia tienen las imágenes en los libros de texto?

- ¿Qué tipos de imágenes utilizan?

- ¿Utilizan los libros de texto recursos para facilitar la interpretación de las imágenes o por el contrario las presentan como si fueran autoevidentes? 
- ¿Cuál es la relación entre el texto y la imagen?

- Además, este estudio analizará si:

- ¿Hay diferencias entre editoriales sobre el uso de las imágenes?

- ¿Existe algún criterio de secuenciación del uso de las imágenes en los diferentes cursos?

En resumen, ¿podemos utilizar los criterios propuestos en este estudio para tomar decisiones sobre qué editoriales tratan más adecuadamente la imagen de manera que los estudiantes puedan aprender y comprenderlas mejor?

\section{METODOLOGÍA}

\section{Clasificaciones de las imágenes}

\section{Tipos de imagen}

Existen diferentes clasificaciones de las imágenes en los libros de texto (Dimopoulos, Koulaidis y Sklaveniti, 2003; Perales y Jiménez, 2002; Postigo y López-Manjón, 2012b). En una primera clasificación, planteamos diferenciar cuatro tipos de imágenes: ilustraciones, diagramas visuales, diagramas verbales y representaciones cuantitativas. Dentro de cada uno de estos grupos estarían incluidos distintos tipos de imágenes más o menos generales o vinculadas a determinados contenidos. Teniendo en cuenta las características de las imágenes en el campo de la biología y en concreto sobre el cuerpo humano, objeto de este estudio, proponemos la clasificación recogida en la tabla 1. Dentro de esta clasificación podríamos considerar como imágenes específicas para la representación del cuerpo humano las fotografías, las imágenes técnicas y los diagramas de estructura y de proceso, porque representan primordialmente relaciones espaciales entre estructuras anatómicas, o procesos situados en estructuras anatómicas. El resto de imágenes (diagramas verbales y representaciones cuantitativas) sería compartido con otros dominios de conocimiento.

Tabla 1.

Clasificación del tipo de imagen

\begin{tabular}{|l|l|l|}
\hline \multicolumn{2}{|c|}{ Tipo de imagen } & \multicolumn{1}{c|}{ Características } \\
\hline \multirow{2}{*}{ Ilustraciones } & Fotografía & $\begin{array}{l}\text { Reproducen todos los elementos externos del fenómeno representado. } \\
\text { Su objetivo habitual es ilustrar. }\end{array}$ \\
\cline { 2 - 3 } & $\begin{array}{l}\text { Imagen técnica: } \text { micro- } \\
\text { fotografía, ecografía } \\
\text { radiografía }\end{array}$ & $\begin{array}{l}\text { Reproducen los elementos internos del fenómeno representado a tra- } \\
\text { vés de diversos medios técnicos (microfotografía: imagen obtenida a } \\
\text { través de microscopio óptico y/o electrónico de barrido; ecografía: } \\
\text { imagen obtenida a través de ultrasonidos; radiografía: imagen obte- } \\
\text { nida por la transmisión de rayos X a través de isótopos radioactivos). }\end{array}$ \\
\cline { 2 - 3 } & Dibujo & $\begin{array}{l}\text { Representaciones icónicas que muestran una correspondencia analó- } \\
\text { gica respecto al fenómeno representado. Son selectivos: recogen algu- } \\
\text { nos aspectos del objeto y su objetivo suele ser ilustrativo o decorativo. } \\
\text { Por ejemplo, un dibujo de frutas y verduras para ilustrar una dieta } \\
\text { saludable. }\end{array}$ \\
\hline
\end{tabular}




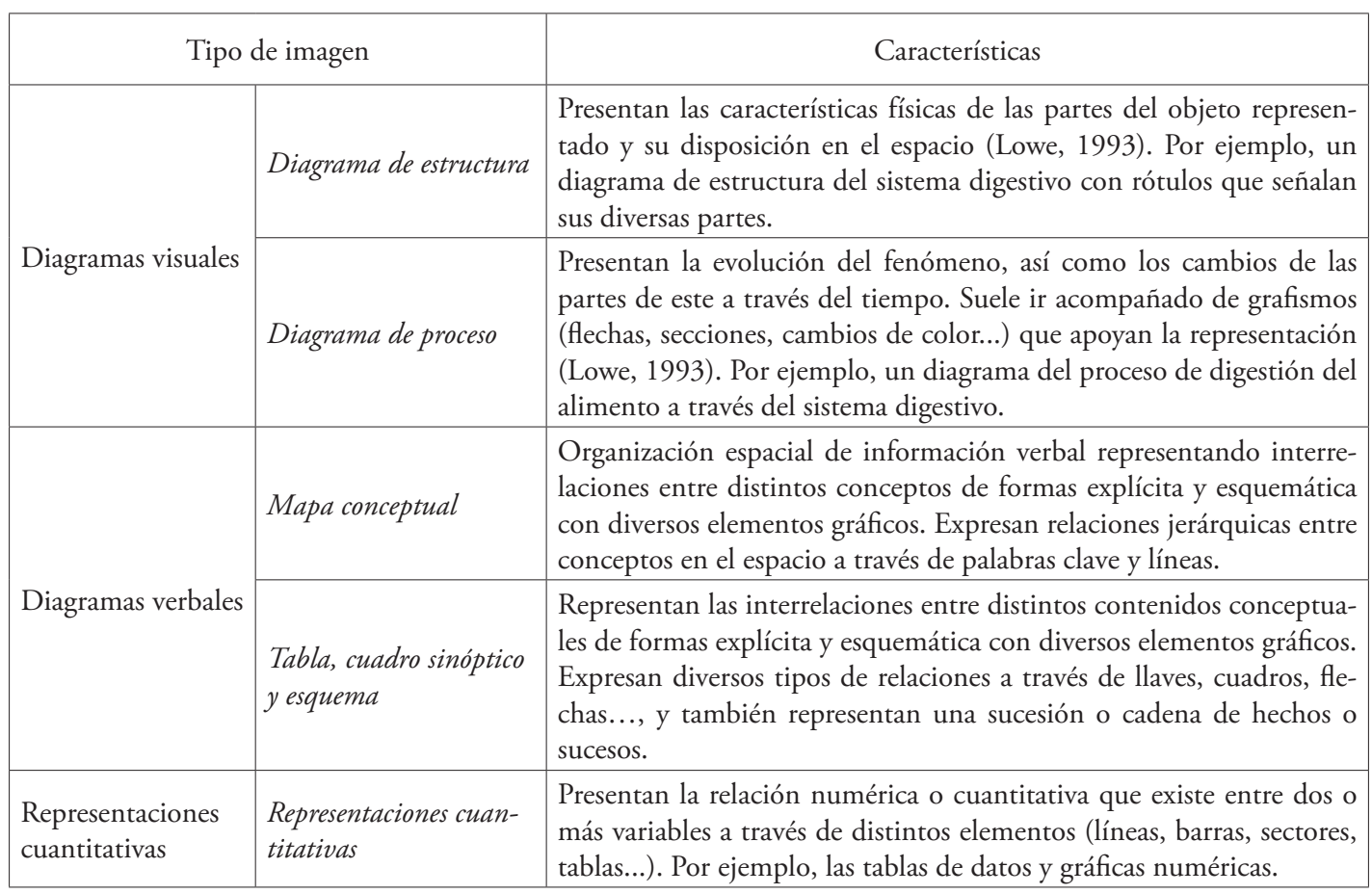

Otra forma de clasificar estas imágenes es según el grado de iconicidad que refleja el grado de realismo de una imagen con un objeto (Perales y Jiménez, 2002), o también según la formalidad del código visual (Dimopoulos, Koulaidis y Sklaveniti, 2003). La clasificación que hemos propuesto en la tabla 1 puede asimismo organizarse según el grado de iconicidad: desde las ilustraciones que reflejarían con mayor realismo el objeto, pasando por los diagramas visuales con un realismo intermedio, hasta los verbales y las cuantitativas como representaciones abstractas. Desde este punto de vista podríamos plantear que existe una relación entre el grado de realismo y la inclusión en los libros de texto de recursos para facilitar su comprensión. De tal manera que los autores de esos libros emplearían menos recursos para las imágenes icónicas o realistas. Sin embargo, las imágenes con un mayor grado de formalismo requerirán un mayor conocimiento del código simbólico por parte del estudiante y consecuentemente deberían incluir más recursos didácticos.

\section{Recursos facilitadores de la interpretación de las imágenes}

Algunos de los recursos, para facilitar la interpretación de las imágenes, son elementos que forman parte de la imagen, entre los que podemos diferenciar componentes visuales y componentes verbales. Los componentes visuales implican el uso de una serie de recursos gráficos, grafismos y colores (por ejemplo, la ampliación de algún detalle del fenómeno, la presentación de diversas perspectivas, el uso adecuado y contrastado de colores, flechas...) que ayudan a una interpretación más profunda y compleja del fenómeno representado. La tabla 2 recoge las características de los nueve componentes visuales considerados en nuestro análisis. 
Tabla 2 .

Características de los componentes visuales de la imagen

\begin{tabular}{|l|l|}
\hline Componentes visuales & \multicolumn{1}{c|}{ Características } \\
\hline Detalles ampliados & $\begin{array}{l}\text { Muestran simultáneamente un fenómeno y el detalle de una parte del fenómeno que se quiere } \\
\text { resaltar a modo de zoom al lado de la imagen (Pérez de Eulate } \text { et al., 1999). }\end{array}$ \\
\hline Secciones o cortes & $\begin{array}{l}\text { Muestran algunos elementos interiores considerados relevantes y que no son visibles desde otras } \\
\text { perspectivas, al mismo tiempo que se observa el exterior del resto del fenómeno (por ejemplo, } \\
\text { cortes transversales, verticales...) (Pérez de Eulate et al., 1999). }\end{array}$ \\
\hline Perspectivas & $\begin{array}{l}\text { Diferentes orientaciones de las formas del fenómeno en el espacio para la representación bidimen- } \\
\text { sional de objetos tridimensionales. Por ejemplo, perspectiva frontal o lateral, lo que permite una } \\
\text { representación más completa. }\end{array}$ \\
\hline $\begin{array}{l}\text { Dos o más representa- } \\
\text { ciones distintas }\end{array}$ & $\begin{array}{l}\text { Representaciones de un mismo objeto a través de al menos dos tipos distintos de imagen. Por } \\
\text { ejemplo, un diagrama de estructura con rótulos y una radiografía de un brazo. Esto facilita la idea } \\
\text { de que un mismo objeto puede tener diferentes tipos de representación. }\end{array}$ \\
\hline $\begin{array}{l}\text { Presencia y/o coexisten- } \\
\text { cia de diferentes planos }\end{array}$ & $\begin{array}{l}\text { Ofrecen diferentes niveles de acercamiento al fenómeno. En el caso del cuerpo humano, también } \\
\text { el uso de planos transparentes permite acceder al interior del cuerpo. }\end{array}$ \\
\hline Contexto & $\begin{array}{l}\text { Elementos que enmarcan o contextualizan en mayor o menor medida el fenómeno representado } \\
\text { con el empleo de elementos abstractos o concretos haciendo referencia a las situaciones en las que } \\
\text { se da ese fenómeno. }\end{array}$ \\
\hline Ubicación & $\begin{array}{l}\text { Elementos que seńalizan la localización de un órgano o aparato en una estructura mayor o en el } \\
\text { cuerpo humano completo. }\end{array}$ \\
\hline Grafismos & $\begin{array}{l}\text { Flechas y líneas en la imagen para indicar la dirección de un proceso o destacar algún aspecto } \\
\text { del fenómeno representado (por ejemplo, uso de flechas indicando los diferentes recorridos de la } \\
\text { circulación sanguínea) (Pérez de Eulate et al., 1999). }\end{array}$ \\
\hline $\begin{array}{l}\text { Diferencian los elementos o los distintos planos de la representación o subraya visualmente la } \\
\text { información relevante para atraer y dirigir la atención (Pérez de Eulate et al., 1999). }\end{array}$ \\
\hline
\end{tabular}

Los componentes verbales son elementos de tipo verbal que de manera más o menos explícita acompañan o complementan la imagen:

1. Título: la presencia y características del título que acompaña a la imagen. Un título puede nombrar únicamente el objeto representado, añadirle información, interrogar al lector fijando su atención en algunas partes de la imagen o hacer referencia explícita a la imagen guiando su interpretación.

2. Referencia al carácter representacional de la imagen en el título: este componente podría ayudar a superar la idea de que la representación es realmente el objeto, a través de la mención explícita en el título de que la imagen es un modelo o representación de un objeto, y en ocasiones también, indicando el tipo de representación (por ejemplo, fotografía de un óvulo tomada al microscopio y esquema de sus partes).

3. Rótulos: presencia o no de etiquetas o rótulos en la imagen que señalan diferentes partes del fenómeno representado (Pérez de Eulate et al., 1999; Perales y Jiménez, 2002), y/o las características de estos, lo que suele ayudar a dar significado a la imagen.

\section{Relación entre el texto y la imagen}

La mención explícita a la imagen en el texto principal también es considerada un recurso para la interpretación de la imagen. Esta relación puede ser de diferente complejidad: desde la mera referencia (por ejemplo, "véase figura») hasta ayudas específicas para el aprendizaje de la imagen. Puede suceder, como muestran otros estudios (Pérez de Eulate et al., 1999; Perales y Jiménez, 2002; Postigo y López-Man- 
jón, 2012b), que no se establezca esa relación y, por lo tanto, la imagen y el texto sean representaciones independientes entre sí. De lo cual se puede deducir que el texto no proporciona ayudas explícitas para la interpretación de la imagen, asumiendo que es fácilmente accesible por el estudiante.

\section{INSTRUMENTOS: CRITERIOS DE ANÁLISIS}

Describiremos las categorías utilizadas para analizar y caracterizar las imágenes. Algunas categorías solo se nombrarán, puesto que ya se han descrito anteriormente.

1. Número de imágenes por página: media de imágenes por página para cada uno de los cursos en las tres editoriales.

2. Tamaño de la imagen: se realizaron dos formas complementarias de medirlo. Una de carácter más global, en la que se analizó el espacio dedicado a las imágenes calculando el porcentaje de ocupación de todas las imágenes en cada página. Y otra más específica, en la que se tenía en cuenta el tamaño de cada una de las imágenes. En este último caso se clasificaron las imágenes en función del porcentaje de espacio que ocupa cada imagen en la página. Se identificaron cinco tamańos con los siguientes porcentajes de ocupación de la página:

- Imágenes muy pequeñas (1-9\%), porcentaje promedio: 5\%

- Imágenes pequeñas (10-19\%), porcentaje promedio: 10\%

- Imágenes medianas (20-34\%), porcentaje promedio: $25 \%$

- Imágenes grandes (35-60\%), porcentaje promedio: 50\%

- Imágenes muy grandes (> 70\%)

3. Tipo de imagen: clasificamos las imágenes en función de los ocho tipos de imagen incluidos en la tabla 1.

4. Otros componentes de la imagen: componentes visuales y componentes verbales. A cada imagen se le adjudicó una puntuación teniendo en cuenta su presencia o ausencia, adecuación y en algunos casos especificando el tipo.

a) Componentes visuales:

1. Detalles ampliados

2. Secciones o cortes

3. Perspectivas

4. Dos o más representaciones distintas

5. Presencia y/o coexistencia de diferentes planos

6. Contexto. Diferenciamos cinco tipos:

0 = no hay contextualización, los órganos no están situados en ninguna silueta;

1 = contextualización mínima, solo se incluye el perfil de la silueta humana;

2 = incluye además de la silueta elementos tales como contorno con color simulando la carne;

3 = contextualización mayor con foto o apariencia más realista que la anterior;

4 = una apariencia como la anterior, añadiendo elementos que aportan más contextualización, como el uso de elementos o actividades de la vida cotidiana (por ejemplo, una flexión del brazo sujetando un vaso o un sombrero).

7. Ubicación

8. Grafismos

9. Colores: adecuados/inadecuados 
b) Componentes verbales:

1. Título: diferenciamos seis tipos $0=$ no hay título; 1 = título descriptivo breve (por ejemplo, aparato digestivo); 2 = título frase expositiva (por ejemplo, frase sobre el aparato digestivo y sus partes); 3 = título interactivo (interacciona o interroga al lector fijando su atención en algunas partes de la imagen, por ejemplo, ¿en qué parte del tronco se encuentran los riñones, en el tórax o en el abdomen?); 4 = título guía o título ayuda (hace referencia explícita a la imagen, ayudando y guiando su interpretación, por ejemplo, mencionar el significado del código de colores azul y rojo del sistema circulatorio); 5 = título mixto suma de las categorías 1 y 2.

2. Referencia o no al carácter representacional de la imagen en el título.

3. Rótulos: ausencia de rótulos, rótulos breves (una o dos palabras) o rótulos narrativos (en forma de frase).

5. Relación del texto con la imagen: si el texto hace o no referencia a la imagen.

\section{CORPUS DEL ESTUDIO}

Se analizaron 399 imágenes correspondientes a ocho libros de texto de $3 .^{\circ}, 4 .^{\circ}$ y $6 .^{\circ}$ curso de primaria de Conocimiento del Medio de tres editoriales (Santillana, SM y Vicens-Vives) de acuerdo con la Ley Orgánica de Educación (LOE) de 2006. Las imágenes seleccionadas pertenecen a las unidades didácticas sobre sistemas corporales por ello seleccionamos de cada editorial sólo aquellos cursos que tratan el tema del cuerpo humano.

Los ocho libros analizados fueron los siguientes:

Santillana, Colección La casa del saber, Departamento de Primaria de Santillana Educación, S.L. Director J. T. Henao (2008), Conocimiento del Medio. 3. ${ }^{\text {er }}$ curso primaria, 215 páginas, 28 páginas analizadas $(13,0 \%)$

Santillana, Colección La casa del saber, Departamento de Primaria de Santillana Educación, S.L. Director J.T. Henao (2008), Conocimiento del Medio. 4. ${ }^{\circ}$ curso primaria, 215 páginas, 12 páginas analizadas $(5,5 \%)$

Santillana, Colección La casa del saber, Departamento de Primaria de Santillana Educación, S.L. Director J. T. Henao (2009), Conocimiento del Medio. 6. ${ }^{\circ}$ curso primaria, 239 páginas, 52 páginas analizadas $(21,7 \%)$.

SM Colección Proyecto Tirolina, Equipo de Educación Primaria. M del Burgo, B. Oro y S. Cáliz (2009), Conocimiento del Medio. 3. ${ }^{\text {er }}$ curso primaria, 207 páginas, 37 páginas analizadas $(17,8 \%)$.

SM Colección Proyecto Tirolina, Equipo de Educación Primaria. M del Burgo, B. Oro, S. Cáliz y A. Moreno (2009), Conocimiento del Medio. 4. ${ }^{\circ}$ curso primaria, 207 páginas, 36 páginas analizadas $(17,4 \%)$.

SM Colección Proyecto Timonel.. R. Fraile, R. Pallol, J. San Andrés, B. Oro, S. Cáliz y N. Pérez (2009), Conocimiento del Medio. 6. ${ }^{\circ}$ curso primaria, 208 páginas, 54 páginas analizadas $(26,0 \%)$.

Vicens-Vives Mundo de Colores. R. Casajuana, M. García, C. Gatell, M. ${ }^{a}$ J. Martínez y J. Serra

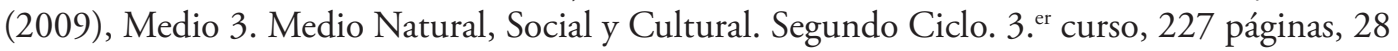
páginas analizadas (12,3\%).

Vicens-Vives Mundo de Colores. R. Casajuana, E. Cruelles, M. García, C. Gatell, M. a J. Martínez y R. Ortega (2009). Medio 6. Medio Natural, Social y Cultural. Tercer Ciclo. 6. ${ }^{\circ}$ curso, 284 páginas, 54 analizadas (19,0\%). 
Las imágenes analizadas son las incluidas en la exposición de contenidos o texto principal y no se consideraron las que aparecen en las actividades. Para un análisis de las imágenes de las actividades, véase Postigo y López-Manjón (aceptado para publicación).

\section{PROCEDIMIENTO}

De acuerdo con los criterios anteriores, ambas autoras analizaron de manera independiente el 33\% de las imágenes de diferentes cursos y editoriales para cada una de las categorías. Se calculó el grado de acuerdo interjueces (coeficiente Kappa) y se obtuvieron valores satisfactorios (oscilando entre ,784 y 1). Posteriormente se hizo un reparto aleatorio del resto de imágenes, también de forma independiente.

Respecto a los análisis estadísticos realizamos análisis descriptivos para cada categoría. Posteriormente realizamos pruebas Chi-cuadrado con residuos tipificados distinguiendo entre: $a$ ) distribución de las categorías en las tres editoriales; $b$ ) distribución de las categorías en los tres cursos, y $c$ ) distribución de las categorías dentro de cada una de las editoriales comparando los tres cursos. El nivel de significación utilizado fue $\mathrm{p}<, 05$. Para todas se interpretaron los residuos tipificados corregidos significativos superiores o inferiores a 2 como más o menos casos de los esperados respectivamente.

\section{RESULTADOS}

Presentamos los resultados en función de los objetivos de este estudio organizados en tres grandes bloques:

\section{En términos generales, ¿̨ómo son las imágenes de los libros de texto?}

De todas las páginas analizadas de los ocho libros, el número promedio de imágenes por página es de 1,4. El porcentaje promedio de página ocupado es del 66,7\%. El tamaño predominante es de imágenes pequeñas $(32 \%$ ) y medianas (38\%), que ocupan respectivamente un 10 y un $25 \%$ de espacio promedio en una página. Hay una escasa presencia de imágenes muy grandes $(6 \%)$.

El tipo de imagen mayoritario son los diagramas de estructura (43,6\%) (figura 1A), seguido de las fotografías $(28,3 \%)$ (figura $1 \mathrm{~B})$. Existe una presencia menor de dibujos (12,5\%) (figura 1C) y diagramas de proceso $(9,5 \%)$ (figura $1 \mathrm{D})$. Cabe destacar la baja frecuencia de imágenes técnicas $(2 \%)$ (figura $1 \mathrm{E}$ ) y mapas conceptuales $(3,3 \%)$ (figura $1 \mathrm{~F}$ ), y la casi inexistencia de tablas, esquemas y representaciones cuantitativas $(0,5$ y $0,3 \%$, respectivamente; figuras $1 \mathrm{G}$ y $1 \mathrm{H})$. Agrupándolas en los cuatro grandes grupos de imágenes mencionados en la tabla 1, la gran mayoría de las imágenes de los libros de texto se distribuyen en dos tipos de imágenes: diagramas visuales $(53,1 \%)$ e ilustraciones $(42,8 \%)$, con escasísima presencia de diagramas verbales y representaciones cuantitativas. 


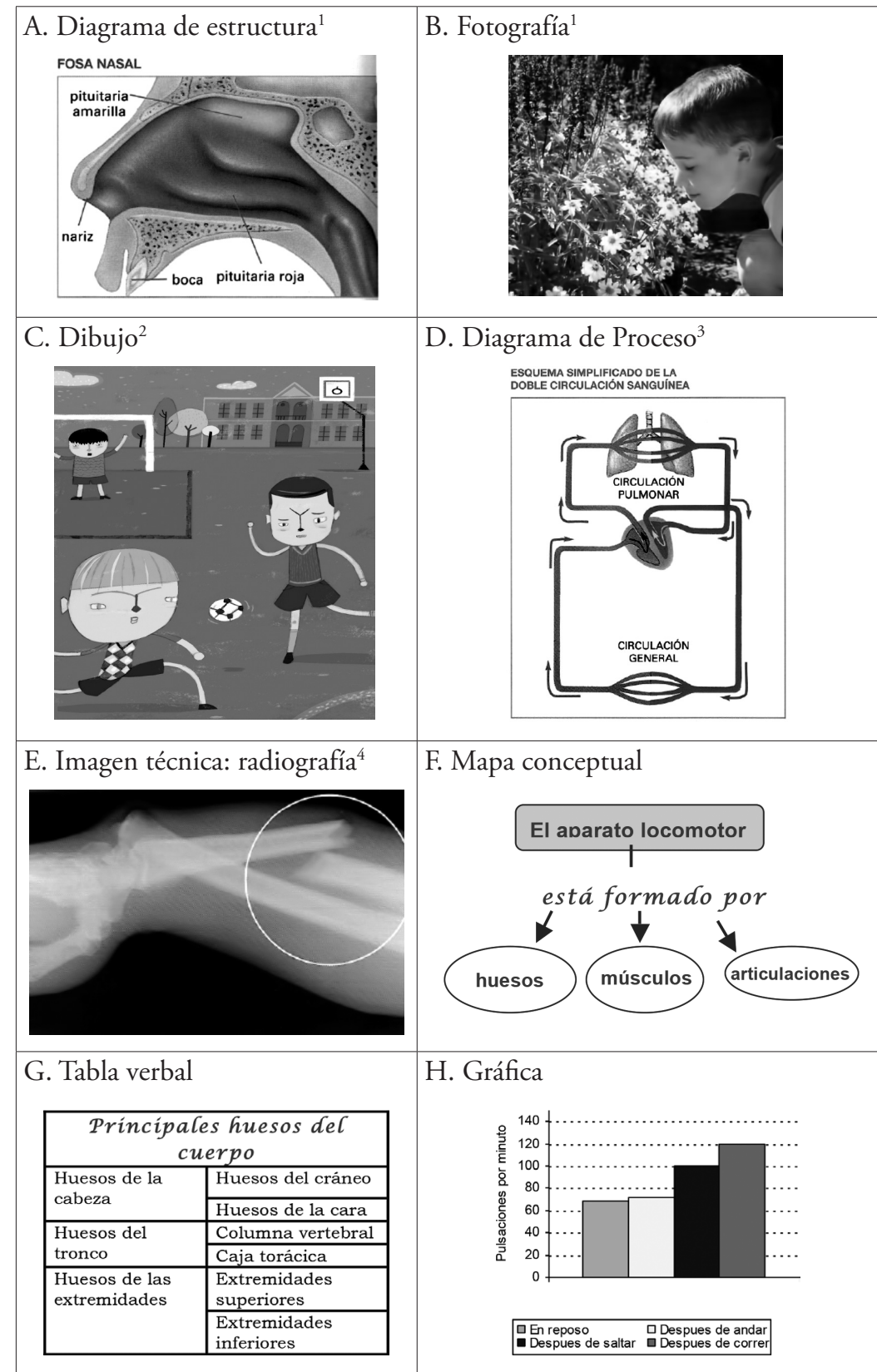

1. Fuente: R. Casajuana, R., M. García, C. Gatell, M. a J. Martínez y J. Serra (2009). Medio 3. Medio Natural, Social y Cultural. Segundo Ciclo. Tercer Curso. Colección Mundo de Colores. Madrid: Vicens-Vives, p. 40.

2. Fuente: Banco de imágenes y sonidos del Ministerio de Educación. Disponible en línea: http://recursostic.educacion.es/bancoimagenes/web/, bajo la Licencia Creative Commons Atribución Compartir Igual 3.0. Ilustrador: Blanca Helga de Miguel Rubio. 3. Fuente: R. Casajuana, E. Cruelles, M. García, M, M. a J. Martínez y R. Ortega (2009). Medio 6. Medio Natural, Social y Cultural. Tercer Ciclo. Sexto Curso. Colección Mundo de Colores. Madrid: Vicens-Vives, p. 201.

4. Fuente: R. Casajuana, E. Cruelles, M. García, M. C. Gatell, M. ${ }^{a}$ J. Martínez y R. Ortega (2009). Medio 6. Medio Natural, Social y Cultural. Tercer Ciclo. Sexto Curso. Colección Mundo de Colores. Madrid: Vicens-Vives, p. 222.

Fig. 1. Ejemplos de la categoría tipo de imagen. 
Los componentes visuales se usan poco, excepto diversas formas de contextualizar las imágenes y los cortes o secciones. También hay que destacar que, en general, hay un uso adecuado de grafismos y colores (tabla 3).

Tabla 3.

Porcentaje de componentes visuales en el total de imágenes de los libros de texto

\begin{tabular}{|l|l|}
\hline \multicolumn{1}{|c|}{ Componentes visuales } & \multicolumn{1}{c|}{ Porcentaje } \\
\hline 1. Detalles ampliados & $7,6 \%$ \\
\hline 2. Secciones o cortes & $23,3 \%$ \\
\hline 3. Perspectivas & $2,6 \%$ \\
\hline 4. Dos o más representaciones distintas & $4,1 \%$ \\
\hline 5. Presencia y/o coexistencia de diferentes planos & $8,1 \%$ \\
\hline 6. Contexto & $37,6 \%$ no contextualizados \\
\hline 7. Ubicación & $62,4 \%$ diversos grados de contextualización \\
\hline 8. Grafismos & $2,6 \%$ \\
\hline 9. Colores & $80,0 \%$ adecuado \\
\hline
\end{tabular}

Los componentes verbales se usan un poco más. Casi la mitad de las imágenes no van acompañadas de título (41,3\%). Los títulos suelen ser, con porcentajes muy similares, descriptivo breve (15,6\%), frase expositiva (16,7\%) o una combinación de ambos (14,4\%). Pocas imágenes tienen un título interactivo $(9,5 \%)$ y solo un 2,6\% tienen un título que de forma explícita ayude a su interpretación.

Salvo muy escasas excepciones la gran mayoría de las imágenes con título no hace referencia al carácter representacional de la imagen (92\%). La mitad de las imágenes no van acompañadas de rótulos (54\%) y las que los presentan son breves de una o dos palabras (38\%). Finalmente, el texto no suele hacer referencia explícita a la presencia de la imagen $(76 \%)$.

Si relacionamos el tipo de imagen con los componentes verbales, encontramos que las fotografías y los dibujos muestran un ausencia de títulos en mayor medida ( 47,7 y $53,3 \%$, respectivamente) que los diagramas de estructura $(35,6 \%)$ y diagramas de proceso $(15,8 \%)$. También existen diferencias en los otros componentes verbales de las imágenes más icónicas o realistas y las más simbólicas. Por ejemplo, hay un $98,2 \%$ de ilustraciones en las que no se menciona la referencia a la naturaleza representacional, frente a un $87,7 \%$ de los diagramas visuales, y un $89,6 \%$ de ilustraciones que no presentan rótulos, frente a un $23,6 \%$ de los diagramas visuales que no presentan rótulos.

\section{¿Existen diferencias entre las editoriales analizadas?}

La media de imágenes por página es similar en las tres editoriales: Santillana: 1,18; SM: 0,98, y VicensVives: 2,02 . 
Tabla 4.

Número de imágenes en cada editorial y curso

\begin{tabular}{|c|c|c|c|c|}
\hline Editorial & Curso & $\begin{array}{l}\text { Número } \\
\text { páginas }\end{array}$ & $\begin{array}{l}\text { Número de } \\
\text { imágenes }\end{array}$ & $\begin{array}{c}\text { Número de imágenes por } \\
\text { página (media) }\end{array}$ \\
\hline \multirow{3}{*}{$\begin{array}{l}\text { Santillana } \\
\text { Colección } \\
\text { La casa del saber }\end{array}$} & $3 .^{\circ}$ & 28 & 29 & 1,04 \\
\hline & $4 .^{\circ}$ & 12 & 9 & 0,75 \\
\hline & $6.0^{\circ}$ & 52 & 71 & 1,37 \\
\hline Total Editorial & & 92 & 109 & 1,18 \\
\hline \multirow{3}{*}{$\begin{array}{l}\text { SM } \\
\text { Colección } \\
\text { Proyecto Tirolina }\left(3 .^{\circ} \text { y } 4 .^{\circ}\right) \\
\text { Proyecto Timonel }\left(6 .^{\circ}\right)\end{array}$} & $3 .^{\circ}$ & 37 & 34 & 0,92 \\
\hline & $4 .^{\circ}$ & 36 & 28 & 0,78 \\
\hline & $6 .^{\circ}$ & 54 & 62 & 1,15 \\
\hline Total Editorial & & 127 & 124 & 0,98 \\
\hline \multirow{2}{*}{$\begin{array}{l}\text { Vicenza-Vives } \\
\text { Colección } \\
\text { Mundo de colores }\end{array}$} & $3 .^{\circ}$ & 28 & 71 & 2,54 \\
\hline & $6 .{ }^{\circ}$ & 54 & 95 & 1,76 \\
\hline Total editorial & & 82 & 166 & 2,02 \\
\hline
\end{tabular}

Respecto al tamaño de la imagen, el porcentaje de página ocupado por las imágenes también es similar (Santillana: 63,8\%; SM: 71,7\%, y Vicens-Vives: 64,8\%), y aunque las tres editoriales presentan fundamentalmente imágenes de tamaño pequeño y mediano difieren en algunos tamaños $\left(\chi^{2}(8, \mathrm{~N}=\right.$ $399)=38,29, p<, 001)$. Así, las imágenes pequeñas son más frecuentes en Vicens-Vives $(42,8 \%)$ y las medianas en Santillana (53,2\%), mientras que las muy grandes, que ocupan más del 75\% de la página, lo son en SM (12,1\%).

En componentes visuales solo hay diferencias en tres de los nueve componentes analizados. Santillana y SM difieren en la categoría presencia de diferentes planos $\left(\chi^{2}(2, N=269)=9,62, p<, 05\right)$, siendo más frecuente en Santillana (14,3\%) que en SM (1,9\%). En Vicens-Vives predomina la no contextualización, presentando imágenes con órganos sueltos (61,5\%); en Santillana, una contextualización intermedia (39,3\% foto o apariencia realista y $11,5 \%$ perfil de silueta humana), y en SM, una mayor contextualización (30,5\% perfil con contorno de carne y 33,3\% actividad de vida cotidiana) $\left(\chi^{2}\right.$ $(8, \mathrm{~N}=244)=85,731, p<, 001)$. Usan el color de forma distinta Santillana y SM $\left(\chi^{2}(2, \mathrm{~N}=193)=\right.$ $22,91, p<, 001)$, siendo más adecuado en SM $(98,6 \%)$ que en Santillana $(67,9 \%)$.

En componentes verbales, Santillana tiene escasas imágenes sin título y predominan fundamentalmente los títulos interactivos y mixtos; en SM se da el patrón inverso, predominando las imágenes sin título y ninguna imagen con título interactivo, mixto o título que ayude a su interpretación, y en Vicens-Vives tampoco hay títulos interactivos pero sí destaca la alta frecuencia de título descriptivo breve en sus imágenes, comparada con las otras dos editoriales $\left(\chi^{2}(10, \mathrm{~N}=390)=187,70, p<, 001\right)$ (figura 2). 


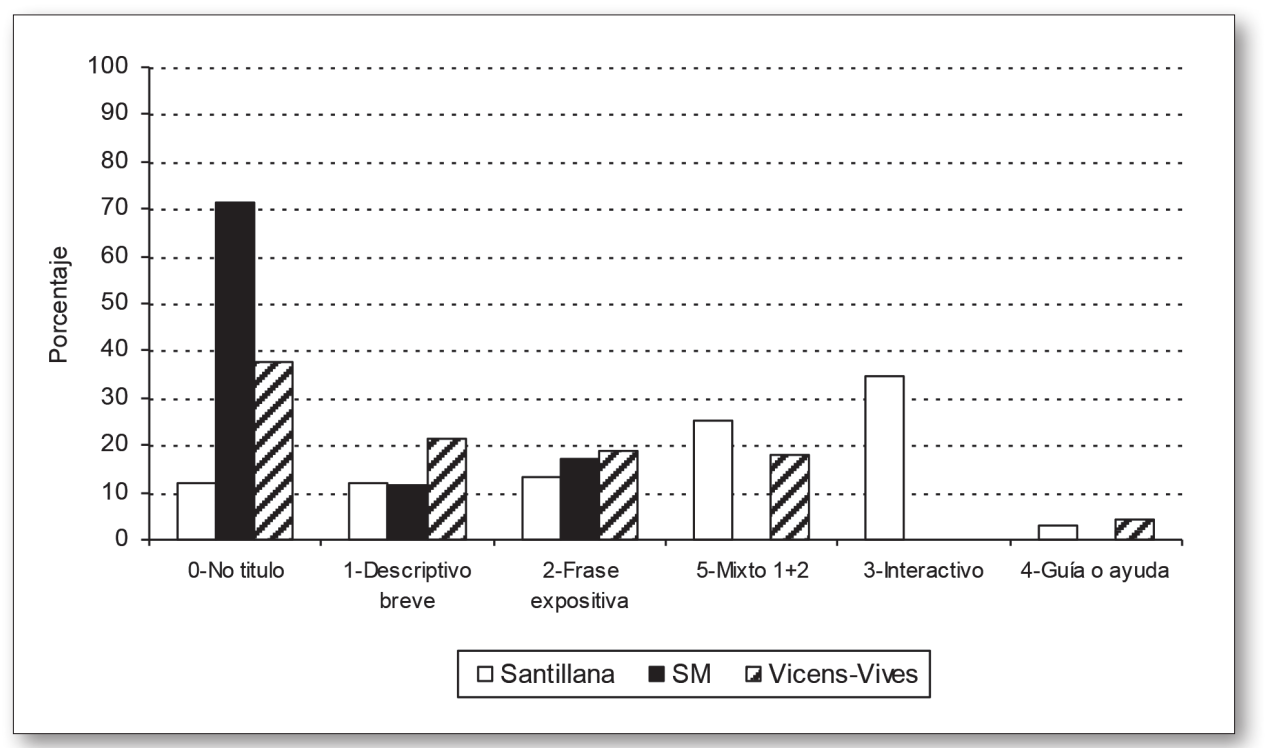

Fig. 2. Distribución del uso de diferentes títulos en las imágenes por editoriales.

Santillana, en casi una cuarta parte de sus títulos, señala el carácter representacional de la imagen $(23,1 \%)$, frente a la escasísima frecuencia en Vicens-Vives $(3,8 \%)$ y nula en $\operatorname{SM}\left(\chi^{2}(2, \mathrm{~N}=391)=\right.$ $46,69, p<, 001)$. Santillana usa más rótulos narrativos $(18,3 \%)$ que $\operatorname{SM}(3,3 \%)\left(\chi^{2}(4, \mathrm{~N}=391)=\right.$ $24,95, p<, 001)$ y hay una referencia explícita a la imagen en la mayoría de sus textos $(88,9 \%)$, lo que no ocurre nunca en SM y Vicens-Vives $\left(\chi^{2}(2, \mathrm{~N}=398)=339,72, p<, 001\right)$.

\section{¿Existe algún criterio de secuenciación en los distintos cursos de primaria analizados?}

Los tres cursos difieren respecto algunos tamaños de las imágenes $\left(\chi^{2}(8, \mathrm{~N}=399)=32,07, p<, 001\right)$. Mientras que las imágenes pequeñas son más frecuentes en tercero (44\%), las de tamaño muy grande se usan más en cuarto $(16,2 \%)$ y las imágenes muy pequeñas en sexto $(17,1 \%)$. En el caso de estos dos últimos cursos utilizan mayoritariamente imágenes de tamaño mediano.

En componentes visuales hay una mayor frecuencia de imágenes con secciones o cortes en sexto curso $(28,2 \%)\left(\chi^{2}(2, N=269)=6,50, p<, 05\right)$. En sexto también es más frecuente $(11,8 \%)$ la presencia de diferentes planos que en tercero $(1,4 \%)\left(\chi^{2}(2, N=269)=8,02, p<, 05\right)$. Con respecto a la contextualización de las imágenes, existen distintos patrones en tercero y cuarto frente a sexto $\left(\chi^{2}(8\right.$, $\mathrm{N}=244)=51,67, p<, 001)$. Así, en tercero y cuarto predomina una mayor contextualización de las imágenes (con actividad de vida cotidiana), contextualización intermedia en cuarto (con foto o apariencia realista) y escaso uso de no contextualización, presentando los órganos sueltos en ambos cursos. Mientras que en sexto se invierte esta tendencia, predominando la no contextualización con órganos sueltos y escaso uso de contextualización intermedia y mayor contextualización. 


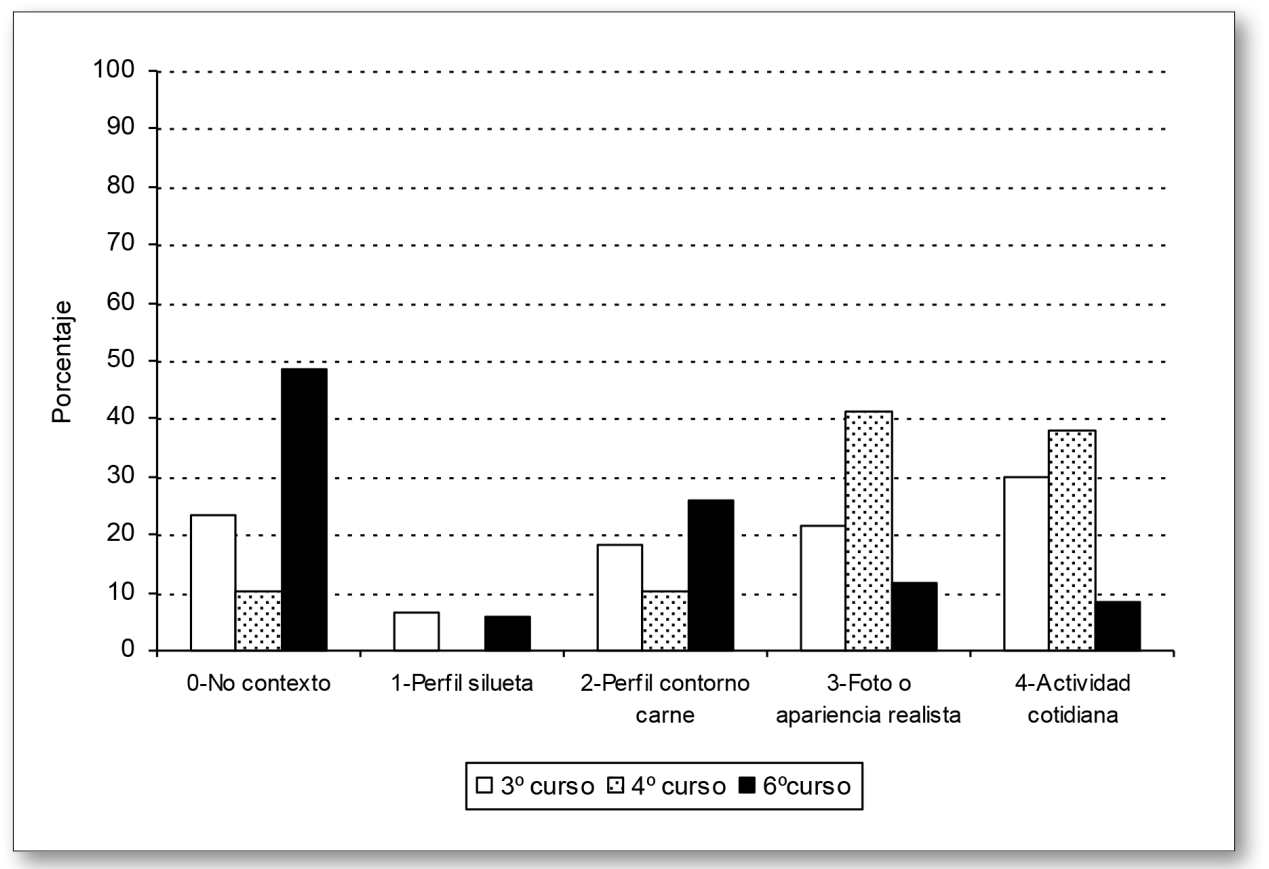

Fig. 3. Distribución de los distintos grados de contextualización de las imágenes por cursos.

En componentes verbales, aunque en términos generales parece que lo más frecuente es presentar las imágenes sin título, entre las que lo presentan hay tres patrones de uso de títulos en los tres cursos $\left(\chi^{2}(10, N=390)=27,82, p<, 05\right)$. En tercero predominan los títulos de frase expositiva $(22,2 \%)$ y títulos mixtos $(21,4 \%)$. En cuarto escasean lo títulos mixtos $(2,7 \%)$ y predominan las imágenes sin título $(56,8 \%)$. Mientras que en sexto escasean los títulos de frase expositiva $(12,8 \%)$ y hay un mayor uso de título interactivo $(12,8 \%)$ y título guía o ayuda (4\%) que en los otros dos cursos. En sexto es algo más frecuente hacer referencia al carácter representacional de la imagen en sus títulos $(11,4 \%)$ que en tercero $(2,4 \%)\left(\chi^{2}(2, N=391)=9,40, p<, 05\right)$. Y, por último, las imágenes sin rótulos predominan en tercero frente a sexto $(62,7$ y $48,7 \%$, respectivamente), mientras que los rótulos narrativos, aunque se utilizan poco, aparecen más en sexto que en tercero (12,3 y 2,4\%, respectivamente) $\left(\chi^{2}(4, \mathrm{~N}=391)\right.$ $=14,67, p=, 05)$.

\section{¿Existe algún criterio de secuenciación del uso de las imágenes por editoriales?}

Solo Vicens-Vives muestra diferencias entre los cursos. Las imágenes pequeñas son más frecuentes en tercero que en sexto $(59,2$ y $30,5 \%$, respectivamente), pero las medianas son más frecuentes en sexto que en tercero $\left(48,4\right.$ y $14,1 \%$, respectivamente) $\left(c^{2}(4, \mathrm{~N}=166)=24,85, p<, 01\right)$. En tercero no hay ninguna imagen con presencia de diferentes planos y un 15,9\% en sexto $\left(c^{2}(1, N=101)=5,72\right.$, $p<$ ,05). Por último, mientras que en tercero predominan los títulos mixtos que combinan título descriptivo breve con frase expositiva $(30,8 \%)$, y no hay ningún título que de forma explicita guíe o ayude a la interpretación de la imagen, en sexto se invierte este patrón con pocos títulos mixtos $(9,5 \%)$ y con una mayor presencia de títulos guía o ayuda $(7,4 \%)$ que en tercero $\left(\mathrm{c}^{2}(4, \mathrm{~N}=160)=16,28, p<, 05\right)$. 


\section{CONCLUSIONES Y DISCUSIÓN}

Los libros de texto analizados conceden una gran importancia a las imágenes, ya que hemos encontrado una media de 1,4 imágenes por página. Además estas ocupan una media del 66,7\% de la superficie de la página. Estos datos son similares a los de otras investigaciones (López-Manjón y Postigo, 2008; Mares, Rivas, Pacheco, Rocha, Dávila, Peñalosa y Rueda, 2006; Pérez de Eulate et al., 1999; Postigo y López-Manjón, 2012b), con una diferencia de hasta veinte años entre los libros de texto analizados. Estos datos muestran el peso adjudicado a las imágenes dada su gran presencia expresada por el número y espacio que ocupan, sin embargo, esto no tiene por qué suponer que se le atribuya un papel importante a las imágenes en esos mismos libros de texto.

Ahora bien, pasemos a comentar cuál es el papel que realmente juegan y qué características tiene este tipo de material. La mitad de las imágenes analizadas son diagramas visuespaciales, mayoritariamente de estructura, que es la manera más común de representar los aspectos anatómicos y estructurales del cuerpo humano. Los aspectos funcionales se representan de forma textual o verbal, dado el escaso porcentaje de diagramas de proceso, que no llega al 10\%. La otra mitad de las imágenes son representaciones de naturaleza más «icónica o realista»: fundamentalmente fotografías y dibujos. La utilización de este último tipo de imagen puede tener varios problemas. Por un lado, el posible carácter decorativo o superfluo de la imagen, considerado tanto por profesores como por alumnos, puede hacer que su papel educativo en el libro de texto sea secundario. Jiménez, Hoces y Perales (1997), en su estudio sobre las imágenes de fuerzas en libros de texto de Física de secundaria y bachillerato, se extrañan de que haya muchas imágenes figurativas, fotos y dibujos, dada la naturaleza simbólica de los objetos representados que demandan otro tipo de imagen. Por otro, la utilización de fotografías y microfotografías, dada su naturaleza polisémica, ya mencionada en la introducción, hace más necesario aún la inclusión de recursos tanto visuales como verbales que ayuden a decidir el significado que se le debe atribuir.

Teniendo en cuenta estos resultados y los de otras investigaciones (Maldonado, González y Jiménez, 2007; Matus et al., 2008; Pérez de Eulate et al., 1999), podemos concluir que no existen ayudas suficientes para guiar la interpretación y comprensión de las imágenes, y por tanto se presentan como si fueran autoevidentes o transparentes. La presencia de componentes visuales en la imagen es escasa: la utilización de detalles ampliados, de al menos dos perspectivas en la imagen, de dos representaciones distintas del mismo fenómeno, de diferentes planos y de elementos que señalen la ubicación de un órgano dentro de una estructura mayor. La presencia de componentes verbales también es escasa: casi la mitad de las imágenes no tienen título, lo que apoya la idea de que la imagen es tan autoevidente que no necesita ser etiquetada ni presentada explícitamente. Además, cuando tienen título rara vez son interactivos, no se interroga al lector fijando su atención sobre algunas partes de la imagen, o poseen títulos guía en los que se hace referencia explícita a la imagen, ayudando y guiando su interpretación. En el mismo sentido, hay una escasísima referencia al carácter representacional de la imagen, por lo que no ayuda a construir la idea de representación de las imágenes necesaria para el aprendizaje de conceptos científicos. Asimismo, la mitad de las imágenes no van acompañadas por rótulos y la otra mitad presenta rótulos breves. Si analizamos el tipo de imagen teniendo en cuenta los componentes verbales, se observa una menor utilización de títulos, rótulos y referencia al carácter representacional de las imágenes en las más icónicas (fotografías y dibujos) frente a las más simbólicas (diagramas visuales), apoyando la idea de que las imágenes más realistas se presentan como si fueran autoevidentes.

Por último, hay un $76 \%$ de imágenes que no son mencionadas explícitamente en el texto, por lo que no se puede utilizar el texto como recurso facilitador del aprendizaje de estas. Por el contrario, esta falta de referencia haría que las imágenes se consideraran, por parte de los alumnos y profesores que utilizan los libros de texto, como «áreas de descanso» (Pérez de Eulate et al., 1999), con una función 
principalmente decorativa, ya que el contenido por aprender y evaluar correspondería a la información incluida en la parte textual del libro. Sin embargo, no hay una ausencia total de recursos visuales, ya que encontramos con cierta frecuencia secciones o cortes $(23,3 \%)$ y, en mayor medida, diferentes grados de contextualización de las imágenes, junto a una utilización adecuada de grafismos y colores.

No obstante, el profesor puede compensar algunas de estas carencias guiando al alumno en el proceso de interpretación de las imágenes, por ejemplo, dirigiendo su atención hacia los diferentes componentes de la imagen, haciendo explícitos sus códigos y convenciones o analizando la adecuación del tipo de imagen al contenido representado, etc. En definitiva, evitando que las imágenes se conviertan en «áreas de descanso» y destacando su importancia como herramienta en el aprendizaje.

En relación con las tres editoriales analizadas, podemos concluir que Santillana es la editorial que trata la imagen de forma más adecuada para ayudar a los alumnos a superar las dificultades que supone el trabajo con imágenes, al incluir una mayor cantidad de recursos visuales y verbales. Específicamente, contiene más imágenes en las que coexisten diferentes planos de un mismo fenómeno. Aunque no contextualiza ni usa el color de manera tan adecuada como las otras editoriales. En donde hay mayor diferencia es en los componentes verbales. Santillana muestra una mayor presencia de títulos y con un carácter interactivo que ayuda a que se interrogue la imagen. Además, en una cuarta parte de los títulos se señala el carácter representacional de la imagen y emplea más rótulos narrativos que las demás editoriales. Por último, el hecho que más distingue a Santillana es la relación entre el texto principal y la imagen. Esta editorial hace mayoritariamente referencia explícita a la imagen en el texto principal, mientras que SM y Vicens-Vives no hacen ninguna referencia, lo que no permite utilizar el texto principal para facilitar el aprendizaje de las imágenes a través de la relación interactiva de ambos formatos.

Dimopoulos et al. (2003) encontraron que aumentaba el nivel de abstracción de las imágenes de primaria a secundaria. En el estudio de Pérez de Eulate et al. (1999), con el que compartimos los mismos cursos de primaria analizados, las imágenes tenían un nivel de complejidad semejante, lo que los llevó a concluir que no existía un criterio de secuenciación en los cursos analizados. En nuestro estudio, comparando las imágenes de tercero, cuarto y sexto cursos de primaria, el único criterio que parece claro es una mayor contextualización en los primeros cursos y menor en los superiores. En este caso, sí parece evidente la existencia de una utilización intencionada de elementos más relacionados con la vida cotidiana al principio, desapareciendo más tarde para dar lugar a imágenes más abstractas. Sin embargo, también se puede interpretar este resultado como una utilización de características más infantiles y decorativas en los primeros cursos, desapareciendo en cursos superiores. También encontramos una mayor presencia de secciones o cortes y de diferentes planos, así como mayor número de títulos interactivos y guía, más rótulos y de carácter narrativo en sexto que en tercero, aunque su frecuencia es muy escasa. Entre las editoriales, Vicens-Vives es la que muestra mayores diferencias entre tercero y sexto en las características anteriores. En resumen, podemos concluir que se utiliza algún criterio de secuenciación en la selección y uso de imágenes a lo largo de los diferentes cursos analizados.

Finalmente hay que señalar que, a pesar de las posibles limitaciones de este estudio por la especificidad del contenido y editoriales analizadas, consideramos relevante caracterizar el tratamiento de las imágenes de los libros de texto por su papel como herramienta educativa contribuyendo a una alfabetización necesaria y urgente ante la omnipresencia de imágenes en la sociedad actual. También creemos que puede proporcionar criterios para que los centros educativos y los profesores puedan seleccionar el libro de texto más adecuado para sus objetivos. 


\section{REFERENCIAS BIBLIOGRÁFICAS}

Andersen, C.; Scheuer, N.; Pérez-Echeverría, M.P. y Teubal, E. (eds.) (2009). Representational systems and practices as learning tools in different fields of knowledge. Rotterdam: Sense Publishers.

Barquero, B.; Schnotz, W. y Reuter, S. (2000). Adolescents' and adults' skills to visually communicate knowledge with graphics. Infancia y Aprendizaje, 90, pp. 71-87. http://dx.doi.org/10.1174/021037000760087973

Bowen, G.M. y Roth, W.M. (2002). Why students may not learn to interpret scientific inscription? Research in Science Education, 32, pp. 303-327. http://dx.doi.org/10.1023/A:1020833231966

Carvalho, G.S.; Silva, R. y Clement, P. (2007). Historical analysis of Portuguese primary school textbooks (1920-2005) on the topic of digestion. International Journal of Science Education, 29 (2), pp. 173-193.

http://dx.doi.org/10.1080/09500690600739340

Carvalho, G.S.; Tracana, R.B.; Skujiene, G. y Turcinaviciene, J. (2011). Trends in Environmental Education Images of Textbooks from Western and Eastern European Countries and Non-European Countries. International Journal of Science Education, 33 (18), pp. 2587-2610. http://dx.doi.org/10.1080/09500693.2011.556831

Colin, P.; Chauvet, F. y Viennot, L. (2002). Reading images in optics: students' difficulties and teachers' views. International Journal of Science Education, 24 (3), pp. 313-332. http://dx.doi.org/10.1080/09500690110078923

Constable, H.; Campbell, B. y Brown, R. (1988). Sectional Drawings from Science Textbooks: An Experimental investigation into pupils' understanding. British Journal of Educational Psychology, 58, pp. 89-102. http://dx.doi.org/10.1111/j.2044-8279.1988.tb00881.x

Del Carmen, L.M. y Jimenez-Aleixandre, M.P. (1997). Los libros de texto: un recurso flexible. Alambique, 11, pp. 7-14.

Dimopoulos, K.; Koulaidis, V. y Sklaveniti, S. (2003). Towards an analysis of visual images in school science textbooks and press articles about science and technology. Research in Science Education, 33, pp. 189-216. http://dx.doi.org/10.1023/A:1025006310503

Fanaro, M.A.; Otero, M.R. y Greca, I.M. (2005). Las imágenes en los materiales educativos: las ideas de los profesores. Revista Electrónica de Enseñanza de las Ciencias, 4 (2), pp. 1-24.

García, J.J. y Perales, F.J. (2007). ¿Comprenden los estudiantes las gráficas cartesianas usadas en los textos de ciencias? Enseñanza de las Ciencias, 25 (1), pp. 107-132.

Jiménez, J.D.; Hoces, R. y Perales, F.J. (1997). Análisis de los modelos y los grafismos utilizados en los libros de texto. Alambique, 11, pp. 75-85.

Jiménez, J.D. y Perales, J. (2002). La evidencia experimental a través de la imagen de los libros de texto de Física y Química. Revista Electrónica de Enseñanza de las Ciencias, 1 (2), pp. 114-129.

Kindfield, A.C.H. (1993/1994). Biology Diagrams: Tools to Think With. The Journal of the Learning Sciences, 3 (1), pp. 1-36.

http://dx.doi.org/10.1207/s15327809jls0301_1

LeE, V.R. (2010). Adaptations and Continuities in the Use and Design of Visual Representations in US Middle School Science Textbooks. International Journal of Science Education, 32 (8), pp. 10991126.

http://dx.doi.org/10.1080/09500690903253916 
López-Manjón, A. y Postigo, Y. (2008). De las representaciones en biología a las ilustraciones de los libros de texto. En G. Mares Cárdenas (ed.). Diseño de psicopedagógico de textos. Diversos enfoques. México: Universidad Nacional Autónoma de México. Facultad de Estudios Superiores Iztacala, pp. 79-110.

López-Manjón, A. y Postigo, Y. (2009). Representations of the human circulatory system. Journal of Biological Education, vol. 43 (4), pp. 159-163.

http://dx.doi.org/10.1080/00219266.2009.9656176

Lowe, R.K. (1993). Successful instructional diagrams. London: Kogan Page.

Lowe, R.K. (2007). Educational illustrations. Western Australia: Savant Publications.

Maldonado, F.; González, F. y Jiménez, M.P. (2007). Las ilustraciones de los ciclos biogeoquímicos del carbono y nitrógeno en los textos de secundaria. Revista Eureka sobre Enseñanza y Divulgación de las Ciencias, 4 (3), pp. 442-460.

Mares, G.; Rivas, O.; Pacheco, V.; Rocha, H.; Dávila, P.; Peñalosa, I. y Rueda, E. (2006). Análisis de lecciones de enseñanza de biología en primaria. Revista Mexicana de Investigación Educativa, 11 (30), pp. 883-911.

MARTí, E. (2003). Representar el mundo externamente. La adquisición infantil de los sistemas externos de representación. Madrid: Antonio Machado Libros.

Martí, E.; García-Mila, M.; Gabucio, F. y Konstantinidou, K. (2011). The construction of a double-entry table: a study of primary and secondary school students' difficulties. European Journal of Psychology of Education, 26 (2), pp. 215-234.

http://dx.doi.org/10.1174/021037000760087946

Martí, E. y Pozo, J.I. (2000). Más allá de las representaciones mentales: la adquisición de los sistemas externos de representación. Infancia y Aprendizaje, 90, pp. 11-30.

http://dx.doi.org/10.1007/s10212-010-0046-1

Matus, L., Benarroch, A. y Perales, F.J. (2008). Las imágenes sobre enlace químico usadas en los libros de texto de educación secundaria. Análisis desde los resultados de la investigación educativa. Enseñanza de las Ciencias, 26 (2), pp. 153-176.

Otero, M.R.; Moreira, M.A. y Greca, I.M. (2002). El uso de imágenes de textos de Física para la enseñanza secundaria y universitaria. Investigaçōes em Ensino de Ciências, 7 (2), pp. 127-154.

Patrick, M.D.; Carter, G. y Wiebe, E.N. (2005). Visual representations of DNA replication: Middle grades students' perceptions and interpretations. Journal of Science Education and Technology, 14 (3), pp. 369-386.

http://dx.doi.org/10.1007/s10956-005-7200-6

Perales, F.J. (2006). Pasado, presente y ¿̨futuro? de los libros de texto. Alambique, 48, versión electrónica.

Perales, F.J. y Jiménez, J. (2002). Las ilustraciones en la enseñanza-aprendizaje de las ciencias. Análisis de libros de texto. Enseñanza de las Ciencias, 20 (3), pp. 369-386.

Perales, F.J. y Vílchez-González, J.M. (2012). Libros de texto: ni contigo ni sin ti tienen mis males remedio. Alambique, 70, pp. 75-82.

Pérez de Eulate, L.; Llorente, E. y Andrieu, A. (1999). Las imágenes de digestión y excreción en los textos de primaria. Enseñanza de las Ciencias, 17 (2), pp. 165-178.

Pérez-Echeverría, M.P.; Martí, E. y Pozo, J.I. (2010). Los sistemas externos de representación como herramientas de la mente. Cultura y Educación, 22 (2), pp. 133-147.

http://dx.doi.org/10.1174/113564010791304519

Pérez-Echeverría, M.P.; Postigo, Y.; López-Manjón, A. y Marín, C. (2009). Aprender con imágenes e información gráfica. En J.I. Pozo y M.P. Pérez-Echeverría (eds.). Psicología del Aprendizaje Universitario. Madrid: Morata, pp. 134-148. 
Postigo, Y. y López-Manjón, A. (2012a). Students' conceptions of biological images as representational devices. Revista Colombiana de Psicología, 21 (2), pp. 265-284 (ISSN: 0121-5469).

Postigo, Y. y López-Manjón, A. (2012b). Representaciones visuales del cuerpo humano: análisis de los nuevos libros de primaria de Ciencias Naturales en la reforma educativa mexicana. Revista Mexicana de Investigación Educativa, 17 (53), pp. 593-626 (ISSN 1405-6666).

Postigo, Y. y López-Manjón, A. Alfabetización gráfica en los libros de texto: análisis de las actividades con imágenes. Infancia y Aprendizaje. (Aceptado para publicación).

Postigo, Y.; Pérez Echeverría, M.P. y Marín, C. (2010). ¿Cómo usan y comprenden los gráficos los estudiantes universitarios? Revista IRICE, 21, pp. 81-94.

Postigo, Y. y Pozo, J.I. (2004). On the road to graphicacy: the learning of graphical representation systems. Educational Psychology, 24 (5), pp. 623-644.

http://dx.doi.org/10.1080/0144341042000262944

Pozzer, L.L. у Roth, W.M. (2003). Prevalence, Function, and Structure of Photographs in High School Biology Textbooks. Journal of Research in Science Teaching, 40 (10), pp. 1089-1114. http://dx.doi.org/10.1002/tea.10122

Roth, W.-M., Pozzer, L. y Han, J.Y. (2005). Critical graphicacy: Understanding visual representation practices in school science. Dordrecht: Springer.

Silva, F. y Compiani, M. (2006). Las imágenes geológicas y geocientíficas en libros didácticos de Ciencias. Enseñanza de las Ciencias, 24 (2), pp. 207-218.

Soyıво, K. (1994). Misleading labelling's in biology textbook drawings. Australian Science Teachers Journal, 40 (2), pp. 10-14.

Stylianidou, F. y Ogborn, J. (2002). Analysis of science textbook picture about energy and pupils' reading of them. International Journal of Science Education, 24 (3), pp. 257-283.

http://dx.doi.org/10.1080/09500690110078905 


\title{
Analysis of human body images in Spanish primary school textbooks
}

\author{
Asunción López-Manjón y Yolanda Postigo \\ Universidad Autónoma de Madrid \\ asuncion.lopez.manjon@uam.es,yolanda.postigo@uam.es
}

Textbooks are the teaching material which has attracted most research due to their important role in the teaching-learning process, particularly in primary and secondary education. Although textbooks have plenty of visual content, there is little research on the role and use of images in textbooks. We conceive images as an external system of representation (Andersen, Scheuer, Pérez-Echeverría y Teubal, 2009). In particular, images as visual representations can convey a great amount of information in a complex way or information that it is difficult to describe in words. Examples of images are: photographs, tables, drawings, graphs, geographical maps, diagrams, etc. The ability to read, understand and construct this external representation is not easy to learn. There is a line of research that shows students' difficulties in learning from images (e.g., Constable, Campbell \& Brown, 1988; López-Manjon \& Postigo, 2009; Colin, Chauvet \& Viennot, 2002; Lowe, 1993; Postigo \& Pozo, 2004; Martí, Garcia-Mila, Konstantinidou \& Gabucio, 2011). Overcoming these difficulties requires implementing explicit teaching processes. We are interested in finding out the extent to which textbooks include any explicit teaching or resources for overcoming students' difficulties with images. There are few studies on this topic and the results need to be taken with caution. They claim that textbooks provide little support for interpreting images due to the limited presence of visual aids such as sections, amplified details and arrows, and that verbal resources are used inadequately (lack of labels and titles and insufficient reference in the main text) (e.g. Postigo and LópezManjon, 2012, Soyibo, 1994). Bowen and Roth (2002) found that images included in scientific journals were less ambiguous and provided more support and context for interpretation than textbook images. We daresay that the visual representations in textbooks are considered self-evident, transparent (Lowe 1993b) and easy to learn. Thus, our aims are first, to determine the features of images in Spanish textbooks to infer whether they take into account the complexity of learning visual information and facilitate student learning. Second, to examine whether there are differences between publishers; and finally, if a sequencing criterion is used for images throughout the different school years.

We analysed 399 images from eight Spanish Natural Sciences textbooks from the $3^{\text {rd }}, 4^{\text {th }}$ and $6^{\text {th }}$ years of primary education (human body only) by three different Spanish publishers. The images were always located beside the main text. We used the following categories: a) Number of images and size; b) Type of image: illustrations (photographs, technical images and drawings), visual diagrams (structure and process), verbal diagrams (conceptual map, table, and charts) and graphs; c) existence of visual and verbal resources for image interpretation and d) referencing the image in the text. The above categories were analysed by the two authors. The degree of inter-rater agreement (Kappa coefficient) was satisfactory, ranging from 0.78 to 1 .

The results show that there are 1.4 images per page and that the surface covered per page is $66.7 \%$. The predominant visual representations are visual diagrams (53.1\%) and illustrations (42.8\%) with few verbal and numerical representations. The rare use of process diagrams, which are some of the most complex representations, was also noticed. Visual resources that help interpret the image are scarce, except for contextualization and surface cut. There are suitable uses of colour and graphic elements. Although the visual resources are more frequent, they are not enough: the title is included in only $60 \%$ of the images, titles which do not help read the image properly and with no reference to its representative nature. Furthermore, only $46 \%$ of the images include labels of different parts and, finally, the text does not make any reference to the image (76\%). The comparison among publishers indicates that one of them provides significantly more resources for learning from images than others. Although rare, there are some sequencing criteria of images along the courses such as size, presence of different levels and types of titles.

We conclude that the textbooks analysed give great importance to visual representations in terms of number of images and their size compared to the text. However, the treatment of the images does not especially help overcome the usual difficulties faced by students since they do not include specific resources that may guide them through their interpretation. Within the limitations of this study, some categories have been offered which are considered useful to evaluate textbooks according to the use of images and their role. 